\title{
Las operaciones personales en la teología trinitaria de Orígenes
}

\author{
Xavier Morales \\ UNIVERSITÉ CATHOLIQUE DE L'OUEST (FRANCE) \\ morales.pro@orange.fr
}

Resumen: El presente artículo examina un famoso pasaje del tratado Sobre los Principios (I, 3, 7) donde Orígenes atribuye operaciones distintas a cada una de las personas de la Trinidad. Una interpretación filológicamente matizada de este pasaje permitirá una valoración teológica de la solución origeniana dentro de la historia de la constitución del axioma teológico omnia opera ad extra communia sunt, que suele ser atribuido a los Padres de la Iglesia.

Palabras clave: Orígenes, Trinidad, Sobre los Principios, historia del dogma cristiano.

Abstract: The present article examines a famous passage from Origen's treatis On the Principles (I, 3, 7), where the Alexandrine assigns different operations to each person of the Trinity. A philologically qualified interpretation of this passage will lead to a theological evaluation of the origenian solution, within the history of the conception of the theological axioma: omnia opera ad extra communia sunt, usually attributed to the Church Fathers.

Keywords: Origen, Trinity, On the Principles, History of Christian doctrines. 


\section{INTRODUCCIÓN}

Las presentes páginas constituyen tan solo el primer fragmento de un proyecto más grande: estudiar cómo los Padres de la Iglesia describieron en clave trinitaria la actuación de Dios en relación con el mundo y los seres creados.

Este es un tema tema clásico, regido por el axioma: Omnia opera ad extra communia sunt. "Todas las operaciones de Dios dirigidas hacia afuera son comunes a las tres personas divinas", como si la Trinidad fuera el único agente de estas operaciones. Este axioma suele ser atribuido a los Padres de la Iglesia ${ }^{2}$. Sin embargo, un examen más matizado de la literatura patrística revela que la idea de una Trinidad como único agente ad extra es el resultado de un largo desarrollo, mientras que la idea opuesta de operaciones propias a las distintas personas divinas también fue sostenida, por ejemplo por Orígenes. Por ahora, me concentro en el Alejandrino, y, aun más precisamente, en un famoso pasaje de su tratado Sobre los principios. En un trabajo más desarrollado, habría que comparar estas páginas con los pasajes de otras obras de Orígenes, sobre todo su Comentario al Evangelio de Juan y su Comentario a la carta a los Romanos, para corroborar y profundizar su interpretación.

A continuación, propondré un breve panorama de la problemática en los Padres del siglo II, que nos proporcionará algunas claves de interpretación para el pasaje mencionado de Sobre los principios.

\section{Breve panorama de la PROBlemática antes de Orígenes}

Por supuesto, la cuestión de las operaciones divinas ya existía antes de Orígenes. En el Evangelio de Juan, Jesús contesta a las preguntas sobre su misteriosa identidad con Dios con una declaración sobre la relación de su actividad con la actividad de Dios: "Todo lo que el [Padre] hace, también el Hijo lo hace semejantemente" 3 (Jn 5, 19). Ahora bien, he demostrado en otro lugar que esta declaración, que parece hablar de dos actividades separadas, en que una imita la otra, apunta en realidad hacia una misteriosa identidad entre ellas ${ }^{4}$.

2 Por ejemplo en B. STuder, Dios salvador en los Padres de la Iglesia. Trinidad - Cristología - Soteriología, (tr. esp., Salamanca 1993) 175.

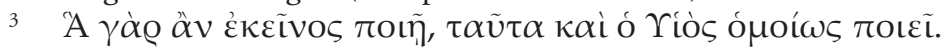

4 X. Morales, Dieu en personnes (Cogitatio Fidei 297, Paris 2015), 50-60. 
Los teólogos del siglo II tuvieron la tarea de traducir esta misteriosa identidad en el lenguaje de la cultura helénica ${ }^{5}$. Justino, por ejemplo, la interpreta con el modelo medio-platónico articulando la transcendencia absoluta del principio y la inmanencia de la causalidad creadora. Sin embargo, esta distinción entre principio transcendente y agente inmanente es peligrosa. Frente a varios sistemas gnósticos que dividen la historia de la revelación de Dios en el mundo entre distintas épocas, época del Padre, época del Hijo y época del Espíritu, Ireneo afirma que el Padre, el Hijo y el Espíritu no actúan como agentes de tres operaciones distintas y sucesivas, sino como agentes de un único proyecto, cada uno con su función propia. Esta unicidad de la economía divina se expresa gramaticalmente en frases donde el Padre es sujeto, el Hijo es complemento

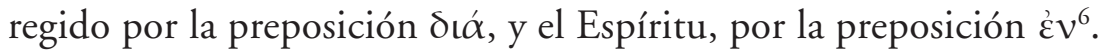

Recordemos esta solución por así decirlo gramatical de la cuestión, porque la vamos a encontrar a lo largo de la tradición patrística. El autor del tratado Contra Noeto, contestando a las acusaciones de triteísmo de sus adversarios monarquianistas, propone una solución más radical: las tres operaciones proceden de una única "potencia", su triplicidad solo se manifieste "del punto de vista de la economía”".

He aquí, pues, las tres direcciones -no excluyentes entre sí- que los Padres van a desarrollar:

1. Dar al Verbo el estatuto de agente inmanente mediador del Padre trascendente. Solución que vamos a llamar "solución escalaria", desarrollada en diálogo con la filosofía medio-platónica.

5 Me inspiro aquí de J. R. Lyman, Christology and Cosmology: Models of Divine Activity in Origen, Eusebius and Athanasius (Oxford 1993) 11-28.

6 Ver X. Morales, La théologie trinitaire d'Athanase d'Alexandrie, 159-162, comentando pasajes de Ireneo De Lyon, Contra los herejes.

7 [Pseudo-] Hipólito, Contra Noeto, 8, 2, en M. Simonetti, Ippolito. Contro Noeto (Bolonia 2000) 168.

8 Se suele hablar de una "ontología escalaria" de tonalidad neo-plátonica. Ver por ejemplo X. BATLLÓ, Ontologie scalaire et polémique trinitaire: le subordinationisme

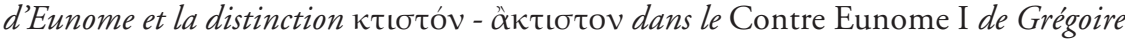
de Nysse (Jahrbuch für Antike und Christentum, Ergänzungsband K. R. 10; Münster 2013); J. Borella, La crise du symbolisme religieux (Lausanne 1990) 55, nota 123, que usa habitualmente esta expresión, atribuye su creación a P. Magnard en un artículo de 1980. 
2. Dar al Padre el estatuto del agente principal de una operación en la cual intervienen las tres personas como tres funciones distintas, descritas mediante el uso de una trinidad de preposiciones alrededor de un único verbo. Llamemos esta solución "solución gramatical" o "solución trifuncional" y notemos cómo se desarrolla en el contexto de la polémica contra el gnosticismo.

3. Distinguir entre una única potencia y operaciones plurales, solución que responde a acusaciones del monarquianismo.

Esta lista de tres soluciones nos va a servir de clave de interpretación.

\section{El tratado Sobre lOS PRINCIPIOS}

Era necesario subrayar los contextos polémicos del desarrollo de estas soluciones, puesto que también en las páginas dedicadas por Orígenes al tema de las operaciones propias de las personas divinas y sus relaciones mutuas, el contexto es polémico, y doblemente polémico: mantener, frente a los monarquianos, la realidad de las distinciones personales, pero salvando la misteriosa identidad frente a varias proposiciones gnósticas?

La interpretación de estas páginas, extraídas de la sección pneumatológica del tratado Sobre los principios, implica riesgos, puesto que no tenemos acceso directo a la versión original griega del tratado. Dependemos de la traducción latina de Rufino de Aquilea ${ }^{10}$.

9 Ch. Kannengiesser, "Écriture et théologie trinitaire d'Origène", en G. Dorival y A. Le Boulluec ed., Origeniana Sexta. Origène et la Bible (Louvain 1995) 351-364, aquí 363, destaca este contexto doblemente polémico.

10 Publicaciones más recientes sobre el tema: S. FERNÁNDEZ, "Gli interventi dottrinali nel De Principiis di Origene”, en M. Girolami (ed.), L'Oriente in Occidente. L'Opera di Rufino di Concordia, Atti del Convegno Internazionale promosso dalla Facoltà Teologica del Triveneto e dal Gruppo Italiano di Ricerca su Origene e la Tradizione Alessandrina (Portogruaro, 6-7 dicembre 2013), (Supplementi di Adamantius IV, Brescia 2014) 23-44; E. PRINZIVAlli, "Origène prédicateur et ses traducteurs latins : la ratio interpretandi de Jérôme et de Rufin", en E. Prinzivalli, Fr. Vinel, M. Cutino et I. Perée, Transmission et réception des Pères grecs dans l'Occident, de l'Antiquité tardive à la Renaissance. Entre philologie, herméneutique et théologie, (Paris 2016) 81-101, sobre todo 95-98. Ver también M. FÉdou, en Origène. Commentaire sur l'Épitre aux Romains, t. I, (SC 532, Paris 2009) 32-34. La tendencia de los últimos treinta años favorece una cierta confianza con la traducción de Rufino, al nivel del contenido, teniendo en cuenta que la traducción no es literal y que Rufino ajusta este contenido al contexto postniceno en que publica su traducción. 
La cuestión sobre las operaciones trinitarias está integrada en la exposición sistemática sobre el Espíritu. Pero Orígenes ya había esbozado elementos de este tema en la sección sobre Cristo. Es preciso tenerlos en cuenta como indicaciones para una interpretación adecuada.

Operaciones divinas en la SeCción SObre Cristo: "espejo de la ACtiVIDAD DE DiOs"

El pasaje más interesante para nuestra tema es el comentario de la cita del libro de la Sabiduría, 7, 26, que menciona explícitamente el concepto de operación o actividad: speculum inmaculatum ève@ $\gamma \varepsilon i ́ \alpha \varsigma$ (id est inoperationis) dei $i^{11}$. La presencia de la palabra griega indica el carácter problemático del concepto de operación. Rufino no la traduce sino que propone un puro calco: en-ergeia $=$ in-operatio, que reaparecerá en la traducción y el comentario de 1 Co $12,6^{12}$.

Orígenes precisa que aquí se trata explícitamente de lo que llamaríamos las operaciones divinas ad extra: creación, providencia, etc. Significativamente, asigna estas operaciones en primer lugar al Padre (solución 2), y no al Logos mediador cósmico de la solución escalaria (solución 1), ni a una substancia única cuyo concepto aparecerá solo bajo la pluma de Basilio de Cesarea (solución 3). Sin embargo, la citación ocurre, con otras, para fundar la idea de una continuidad ontológica entre el Padre y el Hijo ${ }^{13}$. Esta continuidad ontológica está demostrada por una continuidad operativa expresada por lo que he llamado "solución gramatical" o "trifuncional": el Padre es sujeto del verbo de acción, el Hijo es complemento circunstancial regido por la preposición $p^{2} r^{14}$.

Veamos el caso de Sb 7, 26. En una primera interpretación (1. 417423), Orígenes desarrolla la analogía del speculum, suponiendo dos series de operaciones relacionadas entre ellas, una serie original, las

11 Sb 7, 26 citada en PA, I, 2, 12, 1. 411-412 (los textos se citan de acuerdo a la edición de H. Crouzel - M. Simonetti, Origène, Traité des principes, vol. I, Paris 1978, SC 252, p. 138).

12 PA, I, 3, 7, 1. 252, p. 160; PA, I, 3, 8, 1. 286.292, p. 162. Ver también PA, III, 3, 3 y III, 3, 4: energias id est inoperationes.

13 PA, I, 2, 6, 1. 159-161, p. 120.

14 Ver por ejemplo el comentario de $\alpha$ Tóg@oı $\alpha$ id est manatio purissima gloriae omnipotentis (I, 2, 10): Per Filium etenim omnipotens est Pater (I, 2, 10, 1. 341-342). Ver también 1. 346: Per sapientiam qui est Christus, tenet Deus omnium potentatum y 1.374 : Horum autem potentatum gerit per Verbum suum. 
operaciones del Padre, y una serie "imagen", las operaciones del Hijo, $\mathrm{y}$, correlativamente, dos agentes (is qui [...] agit / ea imago quae [...] agit $\left.{ }^{15}\right)$. Sin embargo, Orígenes declara que "los actos y movimientos" de la "imagen" son isdem ipsis, "idénticos" a los actos y movimientos del original. ¿Cómo interpretar esta identidad? ¿Como semejanza exacta o como unicidad? A este punto del texto, Orígenes parece favorecer la primera interpretación, puesto que cita la frase de Jn 5, 19 (1. 423-327): "Todo lo que el [Padre] hace, también el Hijo lo hace semejantemente". Ahora bien, el comentario de este versículo (1. 427-438) nos orienta hacia la segunda interpretación, la de una unicidad.

En primer lugar, Orígenes declara que Jn 5, 19 no habla solo de una semejanza, sino de una unicidad:

"El Hijo no diverge ni difiere en absolutamente nada del Padre por la capacidad de actuar, ni es la obra del Hijo otra obra que la obra del Padre, sino que, por así decirlo, hay también un único e idéntico movimiento en todo" ${ }^{\prime 16}$.

En seguida, el texto vuelve a rechazar la idea de semejanza o imitación, en favor de la identidad como unicidad:

"Las palabras que algunos han dicho según una semejanza o una imitación del alumno hacia el maestro, [...] ¡ ¡ómo pueden convenir, puesto que, en el Evangelio, no se dice que el Hijo hace cosas semejantes, sino que hace las mismas cosas semejantemente"17?

Nos podemos preguntar si no hay aquí una intervención de Rufino. La opinión atribuida aquí a "algunos", la que interpreta Jn 5, 19 "según una semejanza o imitación”, la sostiene el mismo Orígenes en otra lugar, afirmando del Hijo que antes de su incarnación :

"Operaba sin cesar, pues es imitador del Padre"18.

15 PA, I, 2, 12, 1. 417-420, p. 138.

16 PA, I, 2, 12, 1. 428-430, p. 140: In nullo prorsus Filius a Patre virtute operum inmutatur ac differt, nec aliud est opus Filii quam Patris, sed unus atque idem, ut ita dicam, etiam motus in omnibus est.

17 PA, I, 2, 12, 1. 432-438, p. 140: Ea sane quae secundum similitudinem uel imitationem discipuli ad magistrum a quibusdam dicta sunt [...] conuenire quomodo possunt, cum in Euangelio Filius dicatur non similia facere, sed eadem similiter facere?

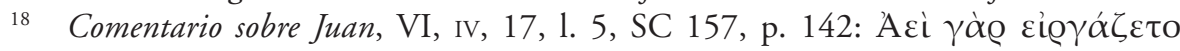

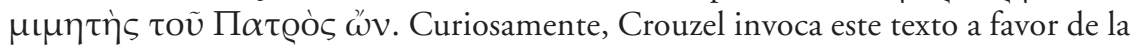
autenticidad del pasaje de PA, SC 253, nota 73, p. 52. 
A lo mejor, Rufino alteró el pasaje para atribuir a otros lo que era una hipótesis propuesta por el mismo Orígenes pero rechazada como "no conveniente". Pero no creo que todo el pasaje deba atribuirse a Rufino. De hecho, se funda sobre un detalle que solo tiene sentido en griego.

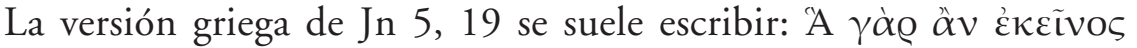

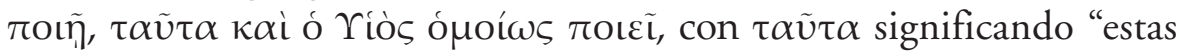
cosas", o sea, en latino: haec, y Rufino entiende así, pues usa la palabra haec cuando traduce Jn 5, 19 en Sobre los principios $^{19}$. Pero el comentario

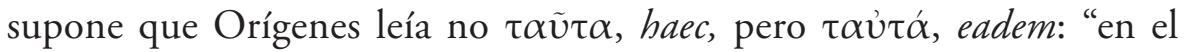
Evangelio, no se dice que el Hijo hace cosas semejantes, sino que hace las mismas cosas semejantemente".

En resumidas cuentas: el texto de Orígenes en su versión original contenía una cierta contradicción, tal vez amplificada por las intervenciones de Rufino, entre proposiciones que suponen dos operaciones distintas, con dos agentes distintos, el Padre y el Hijo, y proposiciones que suponen una única operación. Esta contradicción es el indicio, no de la alteración del texto original por Rufino, sino de una dificultad teológica.

\section{OpERACIONES DIVINAS EN LA SECCIÓN SOBRE EL ESPÍRITU}

Un primer pasaje de la sección de Sobre los principios sobre el Espíri$\mathrm{tu}^{20}$ puede interesarnos.

\section{El ESPÍRITU y LA OPERACión DE REVELACión}

De hecho, el comentario de Is 6, 3 y Ha 3, 2 (PA, I, 3, 4, 1. 91-115, p. 148-150) desemboca en observaciones sobre la operación divina de revelación y sus dimensiones trinitarias. El Hijo no es el único mediador de la revelación divina. El Espíritu también interviene:

PA, I, 2, 6, 1. 161, p. 122 y I, 2, 12, 1. 425, p. 140.

20 No pretendo dar una exposición completa, ni de la pneumatología de Orígenes, ni de toda la sección pneumatológica de PA. Ver últimamente P. Argárate, "The Holy Spirit in Prin I, 3 ", en G. Heidl y R. Somos ed., Origeniana Nona. Origen and the Religious Practice of His Time (Louvain 2009) 25-47 y la bibliografía de la nota 1, p. 25. Para la sección PA, I, 3, 1-4, ver el comentario de F. CocchinI, « Dalla regula fidei reflessioni origeniane sullo Spirito Santo ", en L. Perrone ed., Origeniana Octava. Origen and the Alexandrian Tradition, I, (Leuven 2004) 593-603. 
"Todo conocimiento acerca del Padre, es conocido mediante la revelación del Hijo, en el Espíritu santo, de tal manera que ambos son causa del conocimiento de Dios Padre"21.

Ahora bien, ¿cómo articular estas dos causas de la revelación de Dios?

La primera parte de la frase (de Patre, reuelante Filio, in Spiritu) presenta obviamente lo que he llamado solución gramatical o trifuncional. Pero a continuación, Orígenes parece proponer la solución "escalaria”. Lo que el Espíritu nos revela, él lo conoce porque el Hijo se le ha revelado. Esta solución se deduce del axioma de Mt 11, 27 citado aquí por Orígenes: "Nadie conoce al Padre, sino el Hijo y aquel a quien el Hijo se lo quiere revelar", y también de Jn 16, 14, citado en el Comentario sobre Juan, donde Orígenes presenta la misma interpretación:

"Consta que él también aprende del [Hijo], por lo que dice del Paráclito y Espíritu santo: «Porque tomará de lo mío y os lo anunciará»"22.

Ahora bien, pregunta Orígenes en el Comentario sobre Juan, ¿significa la mediatidad del conocimiento del Espíritu una menor extensión que la del Hijo? Aparentemente, Orígenes deja la cuestión en vilo, pero subraya el "respeto debido al Espíritu santo" ${ }^{23}$. La prudencia de Orígenes pone de manifiesto el riesgo que conlleva la "solución escalaria", de suponer un estatuto ontológico inferior del Espíritu para con el Hijo.

En Sobre los principios, esta solución "escalaria” es rotundamente rechazada24: "No se debe pensar que también el Espíritu conozca mediante una revelación del Hijo" 25 .

21 PA, I, 3, 4, 1. 98-101, p. 150: Omnis enim scientia de Patre, reuelante Filio, in Spiritu sancto cognoscitur, ut ambo [...] causa scientiae Dei patris existant.

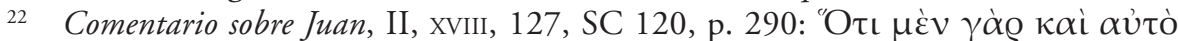

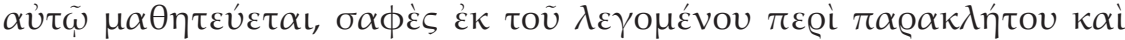

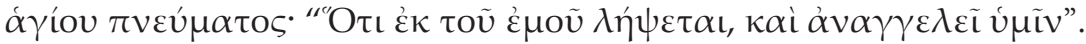

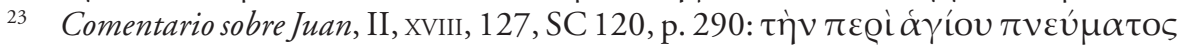
$\varepsilon \dot{u} \lambda \alpha ́ \beta \varepsilon \iota \alpha v$.

24 La solución "escalaria" corresponde a lo que S. FERNÁNDEZ, con M. Simonetti, llama el esquema "vertical" en FPa 27, p. 221, n. 35. S. Fernández comenta que este esquema es "más frecuente en Orígenes", pero que, en este pasaje, se trata de lo que llama esquema "triangular", "que ubica al Hijo y al Espíritu Santo en un mismo nivel bajo el Padre".

25 PA, I, 3, 4, 1. 116, p. 150: Neque enim putandum est etiam Spiritus Filio reuelante cognoscit. 
El motivo de este rechazo ${ }^{26}$ es, precisamente, la cuestión del estatuto ontológico del Espíritu. Si el Espíritu conoce a Dios mediante el Hijo, entonces, "pasa de la ignorancia al conocimiento" 27 , lo que supone un progreso, o sea, un cambio, en el Espíritu. Pero el Espíritu es inconuertibilis $^{28}$, tal como el Padre y el Hijo, y su existencia "trasciende todo concepto temporal" 29 . Por lo tanto, a la subordinación del conocimiento del Espíritu al conocimiento del Hijo, Orígenes sustituye una yuxtaposición que no explica nada: "como el Hijo revela [...] así también el Espíritu santo revela”30.

En resumidas cuentas, las fórmulas matizadas del texto del Comentario sobre Juan y la probable intervención de Rufino en el texto del Sobre los principios, no nos dejan saber, a esta etapa, si Orígenes respalda la "solución escalaria" o si la rechaza para una "solución tri-funcional", donde el Padre es agente de la revelación, el Hijo es mediador, y el Espíritu la lleva a perfección.

26 PA I, 3, 4, 1. 116, p. 150 - 1. 135, p. 152. La contradicción de este rechazo con el Comentario sobre Juan es evidente, a pesar de H. Crouzel, SC 253, p. 64, n. 25, para quien, "en fait il n'y a pas de contradiction", y sugiere una intervención de Rufino. Esta intervención se limita probablemente a la frase que acabo de citar, con la cual Rufino transforma lo que Orígenes quizás proponía como una posibilidad en una proposición rechazada de antemano. Pero casi todo el resto del pasaje (PA, I, 3, 4, 1. 117-129) se encuentra en la Apología de Pánfilo y Eusebio (\$ 76). Cierto es que, en su reciente edición de la Apología, R. Amacker y É. Junod, siguiendo a $\mathrm{R}$. Williams, piensan que este pasaje no figuraba en la versión original, sino que lo agregó Rufino (SC 464, "Annexe: Fiches signalétiques des 70 citations origéniennes de l'Apologie pour Origène", p. 324-335). Sin embargo, me parece inverosímil que Rufino haya insertado el pasaje en la Apología si fuera una pura composición suya y no un texto original de Orígenes.

27 PA, I, 3, 4, l. 117-118, p. 150.

28 PA, I, 3, 4, 1. 127, p. 152. La palabra inconuertibilis (¿gr. ä en la primera rúbrica de la sección de la Apología sobre el Espíritu, que R. Amacker y É. Junod atribuyen a Rufino: Quod eadem sit inconuertibilitas Spiritus Sancti quae Patris et Filii (\$67, SC 464, p. 122; ver p. 123, n. 1, y SC 465, p. 116). PA, I, 3, 4, 1. 135, p. 152: omnem intellegentiam sensus temporalis excedunt.

30 PA, I, 3, 4, 1. 112-113, p. 150 : sicut Filius [...] reuelat cui uult: ita et Spiritus sanctus [...] reuelat Deum cui uult. 


\section{La ACTUACIÓN PROPIA DEL ESPÍRITU}

Llegamos por fin al texto clave para nuestro tema ${ }^{31}$ (I, 3, 5 - I, 4, 2). Orígenes acaba de estudiar el estatuto ontológico del Espíritu. Pasamos ahora del ser al hacer. Tal como era preciso afirmar una subsistencia real del Espíritu, distinsta de la del Padre y de la del Hijo, Orígenes nota que hay una operación del Espíritu, realmente distinta de la del Padre y del Hijo $^{32}$. La llama operatio specialis ${ }^{33}$ :

"Sin embargo, parece menester investigar para saber por qué quien es engendrado por Dios de nuevo para la salvación necesita a la vez el Padre y el Hijo y el Espíritu santo. No recibirá la salvación si la Trinidad no es entera ni es posible participar al Padre o al Hijo sin el Espíritu santo. En esta discusión, será sin duda preciso que describa-

31 Literatura sobre este pasaje controvertido: M. SimONETTI, "Sull'interpretazione di un passo del De Principiis di Origene", en Rivista di Cultura classica e medioevale 6 (1964) 15-32; A. Orbe, La teología del Espiritu santo, Estudios Valentinianos IV (Roma 1966) 533-536; J. DupuIs, L'Esprit de l'homme. Etude sur l'anthropologie religieuse d'Origène (Paris 1967) 119-121; J. Rius-CAMPS, El dinamismo trinitario en la divinización de los seres racionales segun Origenes (Rome 1970) 17-37; H. SAAKE,

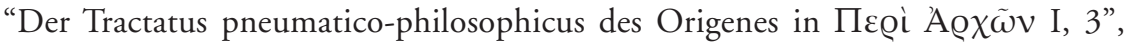
en Hermes 101 (1973) 91-114; IDEM, Pneumatologica. Untersuchungen zum Geistverständnis im Johannesevangelium, bei Origenes und Athanasios von Alexandreia, (Francfort 1973) 35-62; IDEM, "La notion de la Trinité à visée pansotériologique chez Origène et son déplacement intra-ecclésial chez Athanase d'Alexandrie", en C. Kannengiesser (dir.), Politique et théologie chez Athanase d'Alexandrie (Paris 1974) 295-304; H. Crouzel, "Les Personnes de la Trinité sont-elles de puissance inégale selon Origène, Peri Archon 1, 3, 5-8?”, en Gregorianum 57 (1976), 109-125; IDEM, en SC 253, p. 64-70 y Origène, (Paris 1984) 249-250; J. R. Lyman, Christology and Cosmology, 70-72; H. ZiebritzKi, Heiliger Geist und Weltseele. Das Problem der dritten Hypostase bei Origenes, Plotin und ihren Vorläufen, (Tübingen 1994) 203-225.

32 J. R. Lyman, Christology and Cosmology, 71, subraya cómo la distinción de operaciones personales está motivada por la tésis de la subsistencia real de las personas trinitarias: "The essential characteristics of the persons in the Godhead are distinguished by causality and operation".

33 Si bien podemos suponer que operatio traduce $\varepsilon \dot{v} \varepsilon \dot{Q} \gamma \varepsilon\llcorner\alpha$, el adjetivo specialis solo aparece aquí y podría ser una adición de Rufino. Sin embargo, en PA, I, 3, 7, 1. 244, p. 160, encontramos la expresión proprietas operis y, en este caso, proprietas traduce

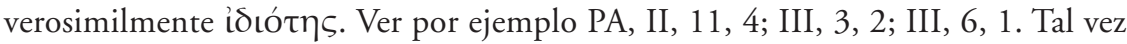
specialis traduce ióí $\alpha$. Ver PA, II, 4, 3, 1. 132, p. 284 donde parece traducir '́oıs, y PA, II, 3, 2 opone generalis causa (1. 77, p. 254) y specialis causa (1. 82, p. 254), y PA, II, 9, 4, opone generalis y specialis singulorum (1. 129, p. 260). 
mos la operación especial del Espíritu santo y la operación especial del Padre y del Hijo" ${ }^{34}$.

Es importante notar que esta discusión sobre las operaciones de las personas divinas, y de su unidad, surge en el marco de la demostración de la naturaleza divina del Espíritu. Su asociación con el Padre y el Hijo al nivel del hacer es prueba de su asociación al nivel del ser. Encontramos la misma coincidencia en el Comentario al Evangelio de Juan ${ }^{35}$, y la encontraremos otra vez en Atanasio de Alejandría, en Basilio de Cesarea, en Gregorio de Nisa.

Cierto es que, como lo comenta H. Crouzel, el pasaje "forma un todo", una "sección" 36 , cuyo "tema central" es "el papel propio de cada persona en la salvación de los hombres" 37 . Sin embargo, no se trata de una nueva sección, supuestamente trinitaria, después de las secciones sobre las determinadas personas divinas. Se trata más bien de una cuestión particular vinculada con el tema del Espíritu. El tema central no es "el papel propio de cada persona", sino "la distinción del papel propio del Espíritu en comparación con el papel propio del Padre y del Hijo". El enfoque sobre el Espíritu explica porque, como en el pasaje que acabo de citar, Orígenes no distingue sistemáticamente entre la operación del Padre y la del Hijo ${ }^{38}$.

Conforme a lo dicho, la operación del Espíritu se especifica por su extensión reducida a los santos, mientras que

34 PA, I, 3, 5, 1. 136-142, p. 152: Rectum tamen uidetur inquirere quid causae sit, quod qui regeneratur per Deum in salutem opus habet et Patre et Filio et Spiritu sancto, non percepturus salutem, nisi sit integra Trinitas; nec possibile sit participem fieri Patris uel Filii sine Spiritu sancto. De quibus discutientes sine dubio necessarium erit ut operationem specialem Spiritus sancti et specialem Patris ac Filii describamus.

35 En el libro II, comentando Jn 1, 3, Orígenes trata de las operaciones trinitarias, e inserta una discusión sobre el Espíritu (Comentario sobre Juan, II, X, 73-88).

36 H. Crouzel, SC 253, p. 64.

37 H. Crouzel, SC 253, p. 65. Consecuentemente, Crouzel intitula I, 3, 5 - I, 4, 2: "De l'action propre de chaque personne", y el pasaje I, 3, 7, 1. 240-269: "Digression: mais l'action de la Trinité est commune". Esta posición es también la de J. Rius-CAmps, El dinamismo trinitario en la divinización de los seres racionales segun Orígenes, 18, n. 1: "El Apéndice sobre el sinergismo de las tres personas divinas en la obra de la salvación (PA I 3,5-4,5) no debe considerarse como parte integrante del Tratado sobre el Espíritu santo”.

38 Ver la anotación de M. SimonetTI, I principi di Origene (Turin 1968), 172, n. 36 : "altre volte ha di mira solo la specificazione dell' attività dello Spirito santo rispetto a quella del Padre e del Figlio complessivamente considerata”. 
"la operación del Padre y del Hijo se extiende tanto a los santos como a los pecadores, a los hombres racionales como a los animales sin palabra, e incluso a los entes sin alma, y a absolutamente todos los que son" 39 .

Esta distinción binaria reaparece en un pasaje que delimita así un primer movimiento (PA, I, 3, 5, 1. 136 - I, 3, 7, 1. 239):

"La operación de la potencia de Dios Padre y del Hijo se extiende sin distinción sobre toda creatura, mientras que, como hemos visto, solo los santos participan al Espíritu santo" ${ }^{40}$.

Otra nota preliminar: Orígenes describe fundamentalmente las operaciones divinas por el concepto platónico de "participación" ${ }^{41}$. La distinción entre operación y participación tiene dos motivaciones. En primer lugar, es una cuestión de punto de vista: "operación" describe la realidad desde el punto de vista de Dios; "participación” describe el resultado en la creatura ${ }^{42}$. Por lo tanto, la descripción de las operaciones divinas no está centrada en la Trinidad en sí, sino en la creatura. La motivación no es puramente especulativa, sino existencial. En segundo lugar, una operación cuyo resultado es una participación, es, por así decirlo, una operación mínima, una operación que no conlleva ninguna modificación o pérdida en el agente. Por lo tanto, salvaguarda la trascendencia divina.

Las operaciones participativas consisten en que Dios da a sus destinatarios una parte de una de sus propiedades esenciales, respectivamente, el ser, la racionalidad o la santidad. Por lo tanto, corresponden a grupos de destinatarios, o participantes, distintos. Ahora bien, como el ser, la racionalidad o la santidad, no son propiedades independientes, sino acumulativas, los grupos de participantes correspondientes se forman, al

39 PA, I, 3, 5, 1. 143-146, p. 152: operationem quidem esse patris et filii tam in sanctis quam in peccatoribus, in hominibus rationabilibus et in mutis animalibus, sed et in his, quae sine anima sunt, et in omnibus omnino quae sunt.

$40 \quad$ PA, I, 3, 7, 1. 226-228, p. 158: Operatio virtutis Dei Patris et Filii indiscrete super omnem protenditur creaturam, Spiritus vero sancti participationem a sanctis tantummodo haberi invenimus. Pasaje citado en Apología, \$ 80, SC 464, p. 134.

41 Ver Kellen Plaxco, "Participation and Trinity in Origen and Didymus the Blind", en A.-Ch. Jacobsen (ed.), Origeniana Undecima. Origen and Origenism in the History of Western Thought (BETL 279; Leuven 2016) 767-782. No he podido leer su comunicación: “The Place of the Spirit in Origen's Taxological Grammar of Participation", Society of Biblical Literature, San Diego, noviembre 2014.

42 Como lo nota P. Argárate, "The Holy Spirit in Prin I, 3”, 43. 
fin y al cabo, por extensiones graduadas: el grupo de los participantes al ser es el grupo de máxima extensión, luego viene el grupo de los participantes al ser $y$ a la racionalidad, y por fin el grupo de los participantes al ser, la racionalidad $y$ la santidad. El problema surge cuando estos grados de extensión, o "escala", en las participaciones los hacemos corresponder con cada una de las personas divinas, dejando suponer que la extensión de sus poderes es también graduada. Las personas divinas no tendrían un igual poder, y por lo tanto, no tendrían una misma naturaleza, lo que contradice la teología trinitaria de finales del siglo IV. Este paso de una gradación funcional a una gradación ontológica parecerá evidente a los lectores postnicenos de Orígenes, como Jerónimo o Justiniano, como veremos más abajo.

El primer movimiento que acabo de delimitar describe sucesivamente la operación especial del Padre y del Hijo (I, 3, 6, 1. 155-195), y luego la operación especial del Espíritu (I, 3, 6, 1. 195-I, 3, 7, 1. 239).

La descripción de la operación del Padre y del Hijo es bastante confusa, puesto que, en realidad, bajo el título operatio Patris et Filii, Orígenes ahora distingue entre una operación del Padre y una operación del Verbo. He aquí la operación del Verbo:

"La operación del Padre y del Hijo se extiende tanto a los santos como a los pecadores. Lo manifiesta el hecho de que todos los entes racionales participan del Verbo de Dios, o sea, de la Razón, y por lo tanto, llevan dentro como unas semillas de sabiduría y justicia, que es Cristo" ${ }^{\prime 3}$.

Sigue la operación del Padre:

"Del que verdaderamente es, el que dijo por Moisés: «Yo soy el que soy», todos los que son participan. Esta participación de Dios Padre se extiende a todos, tanto los justos como los pecadores, los racionales, los irracionales, y absolutamente todos los que son" ${ }^{\text {"4t }}$.

43 PA, I, 3, 6, 1. 155-159, p. 154: Quia autem operatio Patris et Filii et in sanctis et in peccatoribus sit, manifestatur ex eo quod omnes, qui rationabiles sunt, Verbi Dei, id est rationis, participes sunt et per hoc uelut semina quaedam insita sibi gerunt sapientiae et iustitiae, quod est Christus.

44 PA, I, 3, 6, 1. 159-163, p. 154: Ex eo autem, qui uere est, qui dixit per Moysen: "Ego sum qui sum", omnia quae sunt participum trahunt; quae participatio Dei Patris peruenit in omnes tam iustos quam peccatores et rationabiles atque irrationabiles et in omnia omnino quae sunt. 
En la Apología para Orígenes, Rufino propone una versión distinta de estas líneas, que me parece más auténtica:

"Pero el hecho de que toda creatura es y permanece <en el ser>, es operación de Dios Padre, que dijo: «Yo soy el que soy», <operación> que se extiende a todos. Pues el es quien hace salir su sol sobre buenos y malos, y llueve sobre justos e injustos (Mt 5, 45)" ${ }^{\prime 45}$.

\section{¿Una ÚNICA OPERACIÓN EN LA TRINIDAD?}

La descripción de la operación especial del Espíritu se apoya en varios pasajes de la Escritura. El último, Mt 12, 32 ${ }^{46}$, desemboca en una cuestión particular ${ }^{47}$ (PA, I, 3, 7, 1. 240-245). Al principio de la sección sobre el Espíritu, Orígenes había notado "cuanta majestad" este pasaje suponía en el Espíritu santo ${ }^{48}$. Ahora, corrige una posible falsa interpretación: que el Espíritu opere solo sobre los santos no significa que tenga una "dignidad mayor" ${ }^{49}$ que la del Padre y del Hijo.

En el Comentario al Evangelio de Juan (II, XI, 79-81), Orígenes se enfrente a la misma posible falsa interpretación. El hecho de que "todos los entes racionales participan de Cristo, mientras que solo los que son dignos participan del Santo Espíritu" ${ }^{50}$ no debe llevar a creer que "el Es-

45 PÁnfilo y Eusebio, Apología, $\$ 78,1.23-26$, SC 464, p. 132-134: Sed et hoc ipsum quod est et permanet omnis creatura, operatio est Dei Patris, qui dixit: "Ego sum qui sum", quae peruenit super omnes; ipse est enim qui solem suum oriri iubet super bonos et malos et pluit super iustos et iniustos. El hecho de que tengamos dos versiones distintas aboga por la autenticidad global del pasaje. Rufino suprime de la versión de la Apología la cita de Mt 5, 45, modifica el principio del pasaje para oponerlo más claramente a lo que precede (manifestatur ex eo quod omnes... / Ex eo autem...) y acaba con un recuerdo de la tésis enunciada en PA, I, 3, 5.

46 PA, I, 3, 7, 1. 232-239. Líneas citadas en PÁnfilo y Eusebio, Apología, \$ 80, SC 464, p. 134.

47 PA, I, 3, 7, 1. 240-245. La autenticidad de este pasaje parece corroborada por ATANASIO, EpSer IV, como veremos más lejos.

48 PA, I, 3, 2, 1. 51-55, p. 146.

49 PA, I, 3, 7, 1. 244, p. 160. El contexto es probablemente polémico. M. BARNeS, "The Beginning and End of Early Christian Pneumatology" en Augustinian Studies 39 (2008), 169-186, supone el contexto de una "hyper-pneumatology" de marco judeo-cristiano (182), tal como la del Evangelio de los Hebreos, que, afirmando el Espíritu es madre del Logos contradice, según Orígenes, la venida del Espíritu al ser mediante el Verbo (Comentario sobre Juan, II, XII, 87, SC 120, p. 262).

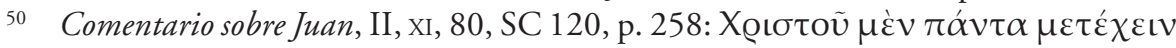
$\tau \dot{\alpha} \lambda$ оо 
píritu santo sea de mayor dignidad que Cristo" 51 . Al revés, puesto que, según Jn 1, 3, "todo llegó a ser mediante" el Verbo, el Espíritu, como todos los entes, llega a ser mediante el Verbo, y es "inferior a aquel mediante el cual llega a ser" 52 .

En Sobre los principios, Orígenes no invoca a Jn 1, 3, o quizá lo hacía pero Rufino no conservó el pasaje, evidentemente porque la subordinación del Espíritu al Verbo según Jn 1, 3, se oponía demasiado a la ortodoxia postnicena. Propone otro argumento, claramente delimitado por una proposición y una recapitulación (PA I, 3, 7, 1. 245-269). He aquí la proposición:

"Es que hemos descrito la especificación de la gracia y de la obra del [Espíritu]. Además, nada en la Trinidad puede decirse mayor o menor" ${ }^{\prime 3}$.

Esta proposición responde a la problemática que he subrayado más arriba. Las especificaciones de las operaciones divinas, descritas como grados de extensión en las participaciones, no introducen grados en las personas operantes. La Trinidad es una, como lo afirma la recapitulación:

"Después de esta exposición preliminar sobre la unidad del Padre, del Hijo y del Espíritu Santo, regresemos ahora al orden" ${ }^{n 4} \ldots$

Ahora bien, la idea de la unidad de la Trinidad resuena con una tonalidad típicamente postnicena que hace sospechar una intervención de Rufino ${ }^{55}$. Por lo tanto, la autenticidad de todo este pasaje bien delimitado $^{56}$ es controvertida. Sin embargo, no carece de rasgos típicamente

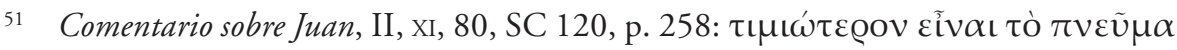

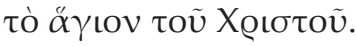

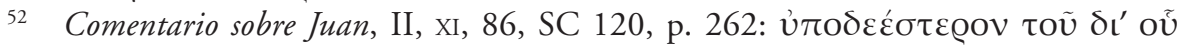

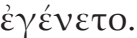

53 PA, I, 3, 7, 245-247, p. 160: Proprietatem namque gratiae eius operisque descripsimus. Porro autem nibil in Trinitate maius minusue dicendum est.

54 PA, I, 3, 8, 270-271, p. 162: His igitur de unitate Patris et Filii ac Spiritus sancti protestatis, redeamus nunc ad eum ordinem...

55 Tanto en PA, I, 2, 6, 1. 160, p. 122 (H. Crouzel, SC 253, p. 40, n. 35) como en I, 3, 4, 1. 126, p. 152 (H. Crouzel, p. 64, n. 26) y aquí, la expresión es controvertida. Se encuentra de nuevo en la recapitulación final del tratado, vinculada con el tema de las operaciones especiales (PA, IV, 4, 5, 1. 188, SC 268, p. 412; y H. Crouzel, SC 269, p. 258, n. 41).

56 H. Crouzel lo titula: "Digression”, SC 252, p. 161. Por falta de sitio, no puedo entrar en una discusión exhaustiva del supuesto fragmento de Justiniano que $\mathrm{Ru}$ - 
origenianos. De todos modos, Rufino había prometido, en el prólogo a su traducción, que todas sus intervensiones editoriales se basarían en textos origenianos auténticos.

La demostración de la "unidad del Padre, del Hijo y del Espíritu", se divide en dos partes, para las cuales hay paralelos origenianos ${ }^{57}$ :

La primera parte (PA, I, 3, 7, 1. 247-251) está dedicada a una interpretación trinitaria de $\mathrm{Sl} 32$, 6, que encontramos también en el Comentario sobre Juan ${ }^{58}$ :

“... porque hay una única fuente de la divinidad que sostiene todas la cosas por su Verbo, su razón, y que santifica los que son dignos de su santificación por el Espíritu de su boca" ${ }^{\text {" }}$.

La frase presenta lo que he llamado "solución gramatical". El Padre ocupa el puesto de sujeto gramatical. Rige dos verbos de acción (tenere, sanctificare). El Verbo y el Espíritu ocupan el puesto de complementos circunstanciales de instrumento en ablativo. Por lo tanto, el Padre es agente principal, y el Verbo y el Espíritu son solo agentes instrumentales de sus operaciones especiales de providencia y de santificación.

Orígenes citará otra vez Sl 32, 6 en la recapitulación final del tratado, quizás aludiendo a este pasaje ${ }^{60}$. Además, la expresión "fuente de

fino habría omitido y subsituido por esta digresión. Sigo la demonstración de H. Crouzel, SC 253, p. 65-70, para quien no hay omisión flagrante en la versión de Rufino; el testimonio de Justiniano (Justiniano, Carta a Menas, en E. Schwartz ed., Acta onciliorum oecumenicorum, t. III, Collectio sabbaitica contra acephalos et origeniastas destinata, [Berlin 1940] 189-208 [carta], 208-213 [antología], 213214 [anatematismas]; aquí citación I, p. 209, 1. 26-32), es por parte un resumen corroborando la versión de Rufino y por parte una extrapolación polémica.

57 Basilio de Cesarea quizá se acuerda de este pasaje en Contra Eunomio, al invocar Sl 32, 6 y, entre otros, 1 Cor 12, 4-6 para demostrar la naturaleza divina del Espíritu

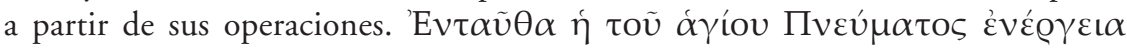

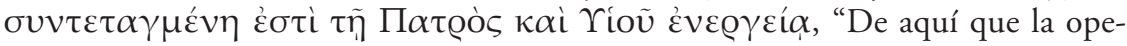
ración del Espíritu santo esté coordenada con la del Padre y del Hijo" (BASILIO DE Cesarea, Contra Eunomio, III, 4, 1. 36-38, SC 305, p. 160; ver también Basilio DE Cesarea, Tratado sobre el Espiritu santo, XVIII, 46, 1. 3-9, SC 17bis, p. 408).

58 Comentario sobre Juan, I, XxIX, 288, SC 120, p. 204.

59 PA, I, 3, 7, 1. 247-249, p. 160: cum unus deitatis fons Verbo ac ratione sua teneat uniuersa, Spiritu uero oris sui quae digna sunt sanctificatione sanctificet.

60 PA, IV, 4, 3, 1. 88-91, SC 268, p. 406. 
la divinidad ${ }^{61 "}$ y lo que he llamado "solución gramatical ${ }^{62}$ ", son rasgos típicamente origenianos:

La segunda parte del pasaje (PA, I, 3, 7, 1. 251-269) está dedicada a 1 Cor 12, 4-6:

"Hay distinciones de dones, pero es el mismo Espíritu; y hay distinciones de ministerios, pero es el mismo Señor; y hay distinciones de operaciones, pero es el mismo Dios, el que opera todo en todo"63.

Hay dos maneras de entender este pasaje.

1. Orígenes reconoce en 1 Cor 12 las tres "operaciones especiales" de las personas, pero nota como Pablo las reduce a una única operación, puesto que el Padre es el agente de todas:

"Además de [lo que describe el Salmo], hay también una operación específica de Dios Padre, por la cual ofrece naturalmente a todos el ser.

Hay también un ministerio específico del Señor Jesucristo, para con los que reciben naturalmente de él el ser racional, por lo cual, además del ser, reciben el ser bien.

Hay también otra gracia, la gracia del Espíritu santo, ofrecida a los que son dignos, administrada por medio de Cristo, pero actuada por el Padre según el mérito de los que se vuelven capaces de recibirla" ${ }^{64}$.

En la última frase reconocemos la "solución gramatical".

61 Orígenes llama al Padre "fuente" en PA, I, 2, 13, 1. 460, p. 142, y lo hace otra vez en PA, I, 3, 8, 1. 290, p. 162. Ver también Comentario sobre Juan, II, 20, SC 120, p. 220; Comentario sobre la carta a los Romanos, IV, 9, 15, 1. 4, SC 539, p. 316, y el artículo de Y. Congar, "Le Père, source absolue de la divinité", en Istina 25 (1980), 237-246, que menciona los pasajes del Comentario sobre Juan y del Comentario sobre Romanos.

62 Ver PA, I, 2, 12, 1. 413-414.

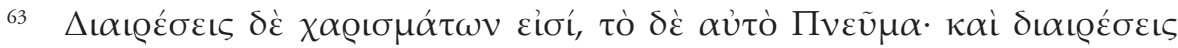

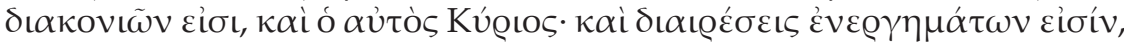

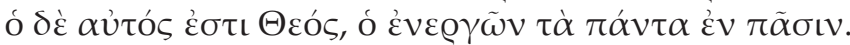

64 PA, I, 3, 7, 1. 256-259, p. 160: Est namque etiam Dei Patris quaedam inoperatio praecipua praeter illam, quam omnibus ut essent naturaliter praestitit. Est et Domini Iesu Christi praecipuum quoddam ministerium in eos, quibus naturaliter ut rationabiles sint confert, per quod ad hoc quod sunt praestatur eis ut bene sint. Est alia quoque etiam Spiritus sancti gratia, quae dignis praestatur, ministrata quidem per Christum, inoperata autem a Patre secundum meritum eorum, qui capaces eius efficiuntur. 
Aquí he seguido lo que J. Rius-Camps llama «la lectura más dificil ${ }^{65}$ », también seguida por la traducción francesa de M. Harl, G. Dorival y A. Le Boulluec ${ }^{66}$. El pronombre illam en la primera frase se refiere a la inoperatio descrita en Sal 32, 16, y quam se refiere a inoperatio praecipua.

2. Pero H. Crouzel propone otra interpretación en su traducción ${ }^{67}$ : illam se vincula con quam, y se refiere a la operación especial de dar el ser, de manera que inoperatio praecipua designaría otra operación distinta (praeter) de la "operación especial" de dar el ser, aunque no se ve cuál. Igualmente, el Verbo, además de su operación especial, actuaría según un "servicio principal" (praecipuum quoddam ministerium), que consiste en dar el ser bien, distinto del ser racional. También el Espíritu daría una nueva gracia, distinta de la gracia de santificación. Nos encontraríamos con una segunda serie de operaciones, distintas de la de operaciones especiales, lo que no me parece coherente con el contexto ${ }^{68}$.

65 J. Ruus-Camps, El dinamismo trinitario..., p. 21-22. La demostración de J. RiusCamps me convence plenamente. En cambio, estoy de acuerdo con la apreciación de H. Crouzel, “The literature on Origen 1970-1988”, en Theological Studies 49 (1988), 499-516, aquí 508, para quien la monografía de Rius-Camps desvía la teología de Orígenes "a little, though not much, in the direction of the Valentinian gnosis".

66 Origène, Traité des Principes, trad. M. Harl, G. Dorival, A. Le Boulluec (Collection des Études augustiniennes - Série "Antiquité» 68; Paris 1976) 54. Los traductores alemanes H. GÖRGEMANNS y H. KaRpP adoptan también esta interpretación, mediante la hipótesis de un error de Rufino, en Origenes. Vier Bücher von den Prinzipien (Darmstadt 1976) 834. Ver también P. Argárate, "The Holy Spirit in Prin I, 3", 43-44.

67 H. Crouzel, SC 252, p. 161. S. FernándeZ propone la misma interpretación en FPa 27, p. 231. Como señala J. Rıus-CAMPs, El dinamismo trinitario..., 21, n. 11, esta interpretación es la de M. SimonetTI, "Sull'interpretazione di un passo del De Principiis di Origene", 23, y I principi di Origene, 177 y n. 52: "due especie di attività"; A. Orbe, La teología del Espíritu santo, 533, n. 4 ("aunque no muy claro en su declaración"); M. GARIJO, "Aspectos de la pneumatología origeniana" (II), en Scriptorium Victoriense 13 (1966), 173-216, aquí 188-200. También es la de H. ZiebritzKi, Heiliger Geist und Weltseele, 216.

68 El mismo Simonetti reconoce que la nueva operación del Padre es "non chiaramente precisata" ("Sull'interpretazione di un passo del De Principiis di Origene", 23), y se niega a distinguir dos operaciones del Espiritu (I principi di Origene, 177, n. 53). Ver J. Dupuis, L'Esprit de l'homme, 118; H. Crouzel, SC 253, p. 75-76; en el caso de H. Ziebritzki, Heiliger Geist und Weltseele, 216-217 y J. S. O'Leary, Christianisme et philosophie chez Origène (Paris 2011) 133-135, la distinción de "deux ordres d'activité des hypostases trinitaires" (O’Leary) se basa claramente en la lectura neo-platónica adoptada. 
Ahora bien, leemos una interpretación semejante de 1 Cor 12 en el Comentario sobre Juan, precisamente en el pasaje sobre Jn 1, 3 y el Espíritu, que quizás es la fuente de Rufino si el pasaje es composición suya:

"La mencionada materia de los carismas es operada a partir de Dios, administrada por el Hijo, y mantenida según el Santo Espíritu”"69.

Notemos que la punta del comentario de 1 Cor 12 no es la distinción de operaciones especiales de las personas. Esto ya lo sabemos desde el principio de la sección. Lo importante es que 1 Cor 12 reduce las distinciones, o diuisiones a la unidad. De hecho, Pablo no habla de tres operaciones o de tres agentes. Idem autem deus qui operatur omnia, "un mismo Dios opera en todo". Solo hay un agente, de manera que, en una fórmula quizá retocada por Rufino, dado su sonoridad típicamente postnicena ${ }^{70}$, solo hay una única operación en la Trinidad, expresada mediante la "solución gramatical":

"Esto lo indica clarísimamente el apóstol Pablo, cuando declara que hay una única e idéntica operación ${ }^{71}$ de la Trinidad. [...] Con estas palabras está clarísimamente significado que no hay ninguna distinción en la Trinidad, sino que lo que se dice don del Espíritu, es administrado mediante el Hijo y operado mediante Dios Padre"72.

He traducido el una uirtus de Rufino por "única operación” y no "única potencia". De hecho, Rufino parece considerar inoperatio y uirtus

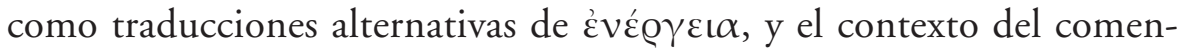

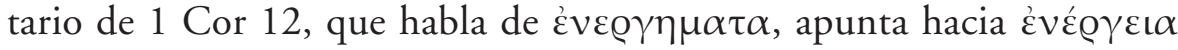

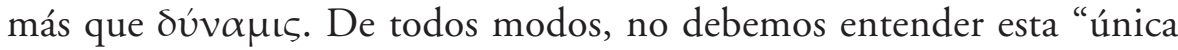

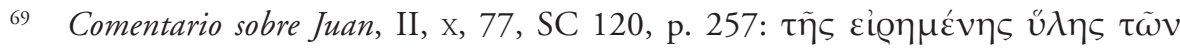

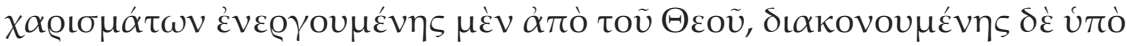

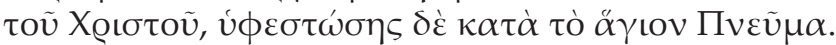

70 Sin embargo, no olvidemos que ya hemos encontrado la idea de una única potencia en el Contra Noeto, y la idea de un "único e idéntico movimiento" en PA, I, 2, 12, 1. 428-430.

71 Por ejemplo en PA, I, 2, 9, 1. 266, p. 128: inoperationis siue uirtutis, pasaje que P. Koetschau, GCS 22, p. 39, comenta hablando de Doppelübersetzung Rufins von

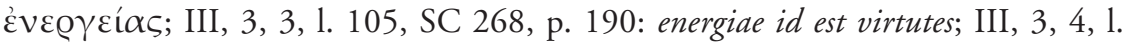
153, SC 268, p. 192: energias id est inoperationes; IV, 4, 1, 1. 50, SC 268, p. 404: uirtus eius inoperatioque.

72 PA, I, 3, 7, 1. 259-261 y 266-269, p. 160-162: Quod manifestissime indicat apostolus Paulus, unam eademque virtutem Trinitatis exponens in eo [...] Ex quo manifestissime designatur quod nulla est in Trinitate discretio, sed hoc, quod donum Spiritus dicitur, ministratur per Filium et inoperatur per Deum Patrem. 
potencia" o "operación" como la afirmación anacrónica del axioma omnia opera... Quizás es un tal anacronismo que explica la corrección de Paul Koetschau en PA, I, 4, 3, que hace reaparecer la idea de una única potencia trinitaria:

Hanc ergo beatam et $\grave{\alpha} \varrho \chi\llcorner\kappa \eta j \nu$, id est principatum omnium gerentem $<\delta \dot{v} \alpha \alpha \mu$ Iv Koetschau $>$ dicimus Trinitatem ${ }^{73}$.

Esta frase no significa: "A esta potencia dichosa y que tiene rango de principio, o sea, que asume el principado sobre todo, la llamamos Trinidad" 74 , o sea, no es una definición de la Trinidad como (única) potencia. Más bien significa: "Por lo tanto, estamos hablando de esta Trinidad dichosa y que tiene rango de principio" 75 , o sea, es una indicación sobre el plan de la sección: después de una digresión sobre la posible caída de los perfectos (PA, I, 4, 1), Orígenes recuerda el tema principal de la sección, las operaciones de Dios para las creaturas.

Más aun, en la frase que sigue, Orígenes no habla de una única potencia, sino de varias potencias (uirtutes Dei), tres potencias, quizá correspondiendo a las tres personas divinas.

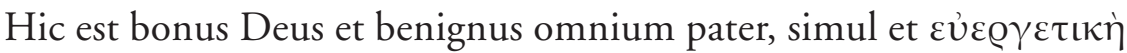

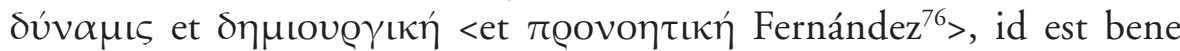
faciendi uirtus et creandi ac prouidendi. Quas virtutes Dei...

"Este Dios es el Dios bueno y el padre benévolo de todo ${ }^{77}$, a la vez potencia de hacer el bien y potencia de crear y potencia providente. Estas potencias de Dios"78...

PA, I, 4, 3, 1. 46-47, p. 168.

74 Contra H. Crouzel y S. Fernández (FPa 27, p. 245), cuyo "principio que administra todo" correspondría más a principatum omnia gerentem.

75 La "Trinidad que tiene rango de principio" aparece en el Comentario sobre Mateo, X, 31, GCS 40, p. 443, 1. 2-3. Como lo señala Koetschau en el aparato crítico, GCS 22, p. 65, la expresión "potencia que tiene rango de principio" también aparece en PA, I, 6, 2, pero, en este lugar, no se trata de la Trinidad.

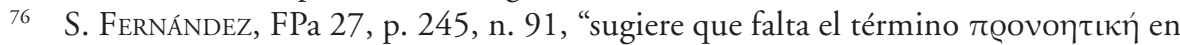
el texto".

77 Como lo sugiere S. Fernández, FPa 27, p. 245, n. 90, pese a la mayúscula «Padre» en la traducción, aquí, Orígenes no se refiere a la primera persona de la Trinidad,

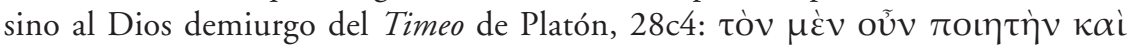

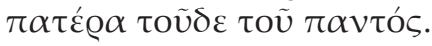

78 PA, I, 4, 3, 1. 47-48, p. 168. 


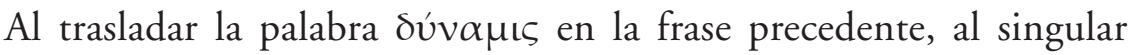
y predicando a la Trinidad, Koetschau fue víctima de un anacronismo inconsciente ${ }^{79}$.

\section{Los GRADOS DEl ITINERARIO DE LA CREATURA HACIA Dios}

Después de esta digression sobre "la unidad de Padre, del Hijo y del Espíritu santo" 80 , Orígenes regresa al tema: "Volvamos ahora al orden que habíamos empezado a discutir" ${ }^{81}$.

"Lo que habíamos empezado a discutir" se refiere al tema enunciado en I, 3, 5: "quien es engendrado por Dios de nuevo para la salvación necesita a la vez el Padre y el Hijo y el Espíritu santo"82. Este tema ha necesitado una discusión sobre "las operaciones especiales" 83 , que, a su vez, desembocó en una digresión sobre "la unidad del Padre, del Hijo y del Espíritu santo" ${ }^{84}$ para equilibrarla. Orígenes puede por fin describir "los grados" del itinerario de la creatura hacia Dios en sus dimensiones trinitarias.

"[Las creaturas] reciben primero el ser de parte de Dios Padre, reciben en segundo lugar el ser racionales de parte del Verbo, reciben en tercer lugar el ser santas de parte del Espíritu santo. Luego, las que ya antes habían sido santificadas por el Espíritu santo se vuelven capaces de [recibir] otra vez a Cristo, puesto que es justicia de Dios. Y los que habían merecido llegar a este grado por la santificación del Espíritu santo, logran sin embargo el don de la sabiduría según el poder de la operación del Espíritu de Dios" ${ }^{\prime 5}$.

79 M. SimonetTi, "Note sulla teologia trinitaria di Origene", p. 286, n. 51, también afirma que aquí, "la Trinità è definita dynamis divina che crea e benefica." Me parece erróneo.

80 PA, I, 3, 8, 1. 270, p. 162.

81 PA, I, 3, 8, 1. 271-272, p. 162: redeamus nunc ad eum ordinem, quem disserere coeperamus.

82 PA, I, 3, 5, 1. 137-138, p. 152.

83 PA, I, 3, 5, 1. 141, p. 152.

84 PA, I, 3, 8, 1. 270, p. 162.

85 PA, I, 3, 8, 1. 278-286, p. 162: Cum ergo primo ut sint habeant ex Deo Patre, secundo ut rationabilia sint habeant ex Verbo, tertio ut sancta sint habeant ex Spiritu sancto: rursum Christi secundum hoc, quod iustitia Dei est, capacia efficiuntur ea, quae iam sanctificata ante fuerint per Spiritum sanctum; et qui in hunc gradum proficere meruerint per sanctificationem Spiritus sancti, consequuntur nibilominus donum sapientiae secundum uirtutem inoperationis Spiritus Dei. 
Orígenes repite su interpretación de 1 Cor 12 que hace corresponder la afirmación de Pablo con las tres operaciones especiales de las personas ${ }^{86}$. Pero ahora se focaliza en una interpretación alegórica de los dones del Espíritu. Puesto que Cristo es "sabiduría, ciencia, santificación" ${ }^{7}$, los dones de sabiduría y ciencia de 1 Cor 12, 8 resultando de la operación especial del Espíritu consisten en una nueva participación de Cristo. Y en último término proceden del Padre, "fuente de todo" 88 , "Dios único que opera todo en todo" 89 (1 Cor 12, 6).

Las últimas líneas de la sección describen el itinerario de la creatura hacia Dios, que parte del Padre y desemboca en el Padre ${ }^{90}$ : a las tres operaciones especiales del Padre, que da el ser, del Verbo, que da la razón, y del Espíritu, que da la santidad, suceden los dones del Espíritu, por los cuales los hombres participan al Hijo a un nivel superior y finalmente

86 Las similitudes entre este párrafo y PA, I, 3, 7 corroboran mi opción de la "lectura más difícil” según la cual la inoperatio praecipua de PA, I, 3, 7 es idéntica a la operatio specialis de PA, I, 3, 5, y no una operación subsidiaria. Un detalle: podemos comparar alia quoque etiam Spiritus sancti gratia de PA, I, 3, 7, 1. 256, p. 160 con la etiam gratia Spiritus sancti de PA, I, 3, 8, 1. 276-277, p. 162 para entender que alia no distingue una segunda gracia en comparación con una primera gracia del Espíritu, pero distingue la (única) gracia del Espíritu de las operaciones del Padre y del Hijo.

87 PA, I, 3, 8, 1. 294-295, p. 162.

88 PA, I, 3, 8, 1. 290, p. 162: uniuersitatis fontem.

89 PA, I, 3, 8, 1. 291, p. 162: diuisiones sunt inoperationum, sed unus Deus, qui ope-

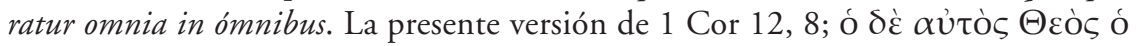
$\dot{\varepsilon} v \varepsilon \varrho \gamma \tilde{\omega} \nu \tau \dot{\alpha} \pi \dot{\alpha} \nu \tau \alpha \dot{\varepsilon} \nu \pi \tilde{\alpha} \sigma \iota v$, difiere de la de PA, I, 3, 7, 1. 263-264, p. 160, más literal: idem autem Deus, qui operatur omnia in ómnibus. Según P. Sabatier, P. SABATIER, Bibliorum sacrorum latinae versiones antiquae, seu vetus italica, III, (Paris 1751) 701, la versión unus autem Deus también se encuentra en autores patrísticos, por ejemplo en Jéronimo, Diálogo contra los pelagianos, I, 29, 1. 54-55, CCSL 80, p. 27, posterior a la traducción de Rufino. Este unus tal vez se explica por una confusión (de Rufino o de Orígenes) con Ef 4, 6.

90 Este itinerario es el tema principal de las monografías de J. Dupuis, L'Esprit de l'homme, y de J. Rius-CAMPS, El dinamismo trinitario... Aquí encontramos el núcleo de los numerosos pasajes de los teólogos capadocios, describiendo trinitariamente el camino de regreso del hombre a Dios. Por ejemplo: Basilio de Cesarea, Tratado sobre el Espiritu santo, IX, 23 y XVIII, 47. Ver X. MORALES, La théologie trinitaire d'Athanase d'Alexandrie, 187-190. 
"pueden recibir Dios"91. Por lo tanto, "la obra (opus) del Padre, del Hijo y del Espíritu santo para con nosotros" es "incesante" (indesinens ${ }^{92}$ ).

En conclusión: la gradación que implicadas en las operaciones trinitarias no tiene un valor teológico sino económico. Describe "los beneficios divinos para con nosotros, que nos son ofrecidos por el Padre, el Hijo y el Espíritu santo" ${ }^{33}$. Sin embargo, Orígenes, preocupado por la distinción real de tres hipostaseis, no llega todavía a la solución de una única operación divina ad extra: afirma la distinción de la operaciones personales, que son realmente operaciones propias $^{94}$, pero matiza esta distinción con una estrecha articulación de estas operaciones, basada en la fontalidad del Padre, y en la "solución gramatical" según la cual el Padre es agente principal, y el Hijo y el Espíritu son instrumentos de la acción paterna ${ }^{95}$.

\section{CONCLUSIÓN}

Intentemos un resumen de nuestra lectura de Sobre los principios:

Por un lado, Orígenes atribuye a cada persona divina una operación propia y exclusiva: las operaciones ad extra atribuidas a las personas no

91 PA, I, 3, 8, 1. 310, p. 164: Deum capere possunt. Por lo tanto, aunque rechazo la teoría de una segunda serie de operaciones específicas, sí se debe hablar de una nueva etapa, de "nuevas e insospechadas perspectivas para el ministerio del Hijo y para la actividad del Padre, en constante y progresivo sinergismo funcional' (J. RiusCAMPS, El dinamismo trinitario, 20).

92 Respectivamente PA, I, 3, 8, 1. 305 y 312, p. 164. En E. Prinzivalli, "Origène prédicateur et ses traducteurs latins: la ratio interpretandi de Jérôme et de Rufin”, 96, comentando un pasaje de Orígenes, Homilia sobre Jeremías, IX, 4, SC 232, p. 292, vemos que inseparabiliter et indesinenter de Rufino corresponden a un sencillo ḋé́.

93 PA, I, 4, 2, 1. 35, p. 168, cerrando la digresión de PA, I, 3, 8, 1. 322, p. 164 - I, 4, 1, 1. 34, p. 168.

94 El comentario de Crouzel, Origène, p. 249, es un poco confuso: Orígenes intenta "discerner le rôle propre de chaque personne dans le gouverment des êtres (appropriations trinitaires), tout en affirmant que leur action est commune". Si se habla de "papel propio", no se puede hablar de "apropiación".

95 En palabras de J. Rius-Camps, El dinamismo trinitario..., 23: "Cada una de las personas tiene, pues, su operación específica, operación que responde intrínsecamente a su manera de ser peculiar, es decir, a lo que constituye primariamente su individualidad y alteridad". "La obra de la salvación (la Economía) es la resultante del concurso divino de las tres personas divinas. En el sistema origeniano podríamos hablar de un 'sinergismo funcional' de las tres personas con vistas a una única operación común" (27), pero "No se trata ciertamente de un 'opus ad extra', común e indiferenciado, de las tres personas" (28). 
lo son por "apropiación", como se hará en la doctrina trinitaria de los escolásticos ${ }^{96}$. Y, consecuentemente, no se habla de una única operación divina ad extra atribuida a una "única substancia", concepto que, de todos modos, Orígenes no conoce.

Sin embargo, y no obstante posibles intervenciones rufinianas, el Alejandrino afirma una cierta unidad entre las operaciones personales, en continuidad con los autores antignósticos o antimonarquianos.

Para describir esta unidad, oscila entre dos soluciones, la solución escalaria y la solución trifuncional:

1. En la solución escalaria, el agente principal es el Verbo, que realiza la voluntad del Padre; el Espíritu recibe del Verbo todo lo que transmite a su vez a las creaturas racionales.

Ahora bien, esta solución escalaria no es exclusiva, de suerte que no se puede reducir Orígenes a las metafísicas escalarias del gnosticismo valentiniano o del neoplatonismo ${ }^{97}$. Sobre todo, es preciso tener en cuenta el contexto polémico donde Orígenes desarrolla esta solución, cuando lo hace. No se trata de salvaguardar la trascendencia del primer principio, sino de subrayar la distinción real de las personas, mediante la distinción de sus operaciones. El Espíritu existe realmente, puesto que tiene una operación propia que no se confunde con la operación de Verbo.

2. En la solución trifuncional, el agente principal es el Padre; el Verbo y el Espíritu colaboran a su obra cumpliendo cada uno su función propia. Debido al acento puesto, en Sobre los principios, sobre la especificidad de su operación, la integración del Espíritu en esta obra unitaria se vuelve difícil. Por ejemplo, el Espíritu parece excluido de la operación

${ }^{6}$ Así J. Dupuis, L'Esprit de l'homme, 119-121.

${ }^{97}$ Aquí me parece importante el diagnóstico de H. Crouzel, "The literature on Origen 1970-1988", en Theological Studies 49 (1988), 499-516, respectivamente sobre J. Rius-Camp y sobre R. M. Berchman, From Philo to Origen: Middle Platonism in Transition (Decatur 1984). Misma posición en M. FÉdou, La voie du Christ. Genèse de la christologie dans le contexte religieux de l'Antiquité du II siècle au debut $d u I V^{e}$ siècle, (Cogitatio Fidei 253; Paris 2006) 408-409: la influencia de modelos platónicos es innegable, pero el proyecto de Orígenes es teológico, no filosófico, y consiste en dar cuenta de la Escritura. H. ZiebritzKi, Heiliger Geist und Weltseele, concluye que la Trinidad cristiana y la doctrina neoplatónica son "zwei konkurrierende metaphysische Entwürfe" (266). 
de creación ${ }^{98}$. Así se verifica lo que notaba al principio: la elaboración de una teología de la Trinidad coherente depende de la cuestión pneumatológica, y cabe decir que, tanto en el caso de Atanasio como en el de Basilio de Cesarea, la elaboración de una teología trinitaria sistemática procederá de una profundización de la cuestión pneumatológica ${ }^{99}$.

La solución trifuncional puede variar, según la intensidad de la cooperación entre las personas divinas. En el caso de Orígenes, la afirmación de tres operaciones distintas ${ }^{100}$ conlleva un cierto subordinacianismo, por lo menos funcional, si no ontológico ${ }^{101}$. Por lo tanto, en el caso de Orígenes, no se puede solo hablar de tres "facetas" de una única operación ${ }^{102}$, pero sí en el caso de Atanasio o más aún de Basilio de Cesarea y de Gregorio de Nisa, cuando el contexto polémico antiarriano impondrá negar todo subordinacianismo. Entonces, la solución trifuncional se reformulará en el marco de la afirmación de una única operación divina, correspondiendo a la única substancia, con la idea de tres causalidades complementarias: eficiente, instrumental y perfectiva: "El Padre confiere el primer ser, el Hijo lo califica racionalmente, el Espíritu santo es la causa perfectiva ${ }^{103}$ ".

98 Como lo demuestra K. MacDonnell en "Does Origen Have a Trinitarian Doctrine of the Holy Spirit?”, en Gregorianum 75 (1994), 5-35.

99 Por ejemplo, en su síntesis de la teología trinitaria de Orígenes, S. FernándeZ habla de "el retraso de la reflexión pneumatológica" (FPa 27, p. 42).

100 Ver J. Rius-Camps, El dinamismo trinitario..., 76: "Según el Alejandrino, no se puede hablar de una obra común «ad extra» de las tres personas -en el sentido en que lo entiende la teología tradicional"-.

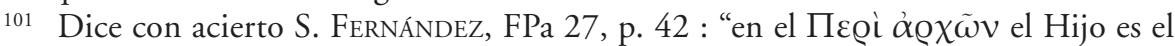
mediador pero no es un ser intermediario”. En cambio, en la solución escalaria, es mediador porque es intermediario.

102 J. Rius-Camps, El dinamismo trinitario..., 76: "Con todo, no debe hablarse de tres operaciones adecuadamente distintas, sino de tres facetas de una sola operación".

103 J. Rius-Camps, El dinamismo trinitario..., 21. J. Rius-Camps aplica esta descripción a la doctrina de Orígenes, lo que no me parece correcto. Pero su aplicación es adecuada en el caso de los Capadocios. 
